\title{
BUSINNES MODEL OF CORS-TR (TUSAGA-AKTIF)
}

\author{
Sedat BAKICI ${ }^{1}$, Bilal ERKEK ${ }^{1}$, Ali İLBEY ${ }^{1}$ and Erkan KULAKSIZ ${ }^{1}$ \\ ${ }^{1}$ GLRC (General Directorate Of Land Registry And Cadastre), Map Department, 06480 Or-An Çankaya Ankara Turkey - (sbakici, \\ berkek, ailbey, ekulaksiz)@tkgm.gov.tr
}

KEY WORDS: CORS-TR (TUSAGA-Aktif), GNSS, Cost/Benefit analysis

\section{ABSTRACT:}

CORS-TR (TUSAGA-Aktif (Turkish National Permanent GNSS Network - Active)), serves location information at cm level accuracy in Turkey and TR Northern Cyprus in few seconds, where adequate numbers of GNSS satellites are observed and communication possibilities are present. No ground control points and benchmarks are necessary. There are 146 permanent GNSS stations within the CORS-TR System. Station data are transferred online to the main control center located in the Mapping Department of the General Directorate of Land Registry and Cadastre.

CORS-TR System was established in 2008 and has been updated in software, hardware, communication and pricing areas from technical and administrative point of view in order to improve the system and provide better service to the users. Thus, the added value obtained from the CORS-TR System has been increased and contributed to the more efficient use of country resources.

In this paper, how the technical, administrative and financial studies in the operation of the CORS-TR System were managed with a sustainable business model, studies for solving problems encountered in operating of the system, the cost / benefit analysis of the system and the sharing of experience gained from the perspective of how web-based applications are managed and the business model of the CORS-TR System are explained in detail.

\section{CORS-TR SYSTEM}

As The General Directorate of Land Registry and Cadastre (GDLRC) and General Command Mapping (GCM) are joint customers of executive Istanbul Kültür University (IKU), "GNNS Stations Network Constantly Observing and National Datum Transformation Project (TUSAGA-Aktif / CORS-TR)" was started on May 8, 2006 and completed by December 2008. The system, which was operated jointly by GDLRC and GCM, was operated free of charge for testing purposes until June 15, 2011, since then, the system has started to be operated at a fixed rate at the Unit Prices determined by the Coordination and Planning Department between the Ministries.

\subsection{CORS-TR System Structure}

CORS-TR System; consist of 2 control centers which are in GDLRC and GCM. And total of 146 stationary GNSS stations which 4 of them are located in Turkish Republic of Northern Cyprus (K.K.T.C.) (Figure 1).

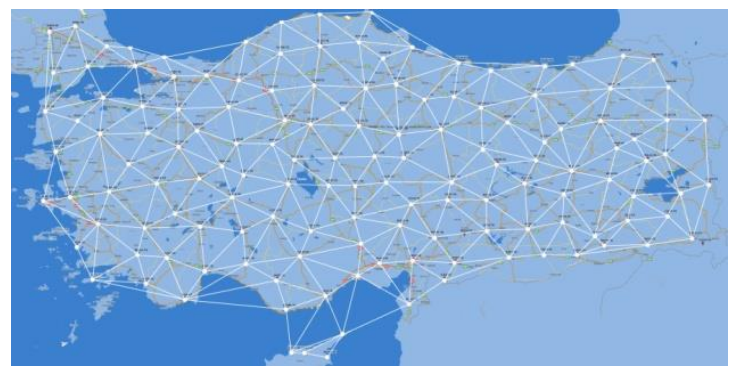

Figure 1. CORS-TR Stations

\subsubsection{Control Centers}

Within the scope of CORS-TR Project, 2 control centers have been set up to be the main control center GDLRC and spare control center GCM. All CORS-TR permanent station data is transmitted automatically to the control center and the calculated Network-RTK correction data is transmitted to the users (Figure 2).

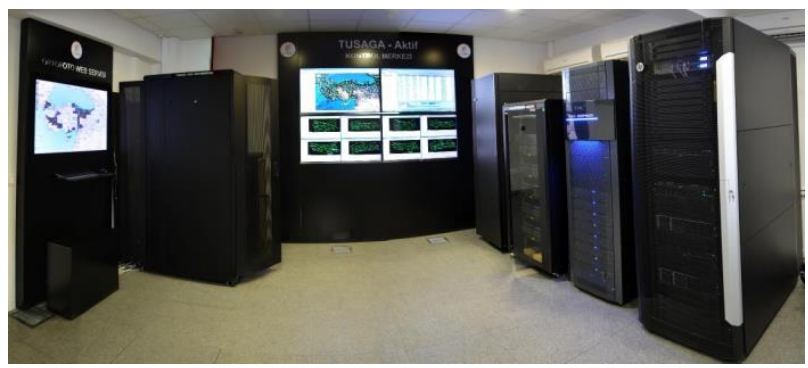

Figure 2. GDLRC CORS-TR Control Center

\subsubsection{Permanent Stations}

The CORS-TR system consists of 146 Permanent GNSS stations, 142 in Turkey and 4 in the TRNC. CORS-TR system's station point locations were determined to have security, electricity and internet infrastructures. CORS-TR system stations are shown in Figure 3. 


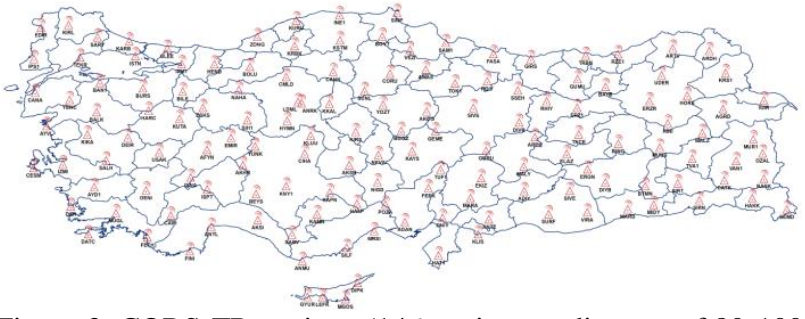

Figure 3. CORS-TR stations (146 stations, a distance of 80-100 $\mathrm{km})$

Ground facilities are planned according to country and region conditions. As a result, two types of floor facilities were decided to be built;

- Concrete floor pillars on soil,

- Large diameter galvanized steel pillars on roofs and terraces.

The distributions of the 146 pylons built throughout the country are as follows;

- 85 units of $2 \mathrm{~m}$ pillars (including floors),

- 58 units of $3 \mathrm{~m}$ pillars,

- 3 units of $4 \mathrm{~m}$ pillars.

\subsection{Working Principle of CORS-TR System}

\subsubsection{Working Principle}

In the CORS-TR system, the observations of GNSS stations located in the reference stations which is covering the whole country with known coordinates are transmitted to a control center over VPN or GPRS / EDGE. In the control center atmospheric and other faults are modeled and RTK / DGPS corrections are calculated in real time and sent to mobile GNSS receivers for positioning via GPRS / EDGE in RTCM format. (Gezer ve Karan ..., 2014)

Real Time Kinematic (RTK) correction data is sent in RTCM (Radio Technical Commission for Aeronautics) communication format and sent to CORS-TR system users via GPRS / EDGE by NTRIP (Network Distribution of RTCM Data over Internet Protocol).

The servers in the control centers calculate the DGPS / RTK correction data by performing atmospheric modeling using the instantaneous data from all the stations. The correction data is transmitted via GPRS / EDGE in NTRIP format. In this way, GNSS receivers use the DGPS data to measure the accuracy in meters, and the RTK data in centimeters.

\subsection{CORS-TR System Users}

\subsubsection{Beneficiary Institutions}

\section{GENERAL DIRECTORATE OF LAND REGISTRY AND} CADASTRE

- Within the scope of the Land Registry and Cadastre Modernization Project (TKMP) Cadastre Renewal works (22-a),

- In forest cadastre and deforested land (2-B) applications,

- Transformation of cadastral maps into ITRFyy system,

- RTK applications,

- Cadastre Directorate applications,

\section{GENERAL COMMAND MAPPING}

-When the conversion parameters between different coordinate systems (ED-50 / WGS-84) are specified,

- In the realization of geodetic applications (coordinate acquisition, point rates, determination of active tectonic movements, etc.)

- As a fixed point service that will remove the reference coordinate system ambiguity in all GNSS studies,

\section{MUNICIPALITIES}

- Current maps,

- Infrastructure and other geographical work,

- e-municipality services,

\section{MINISTRIES}

- Ministry of National Defense,

- Ministry of Forestry and Water Management,

- Ministry of Environment and Urbanization,

- Ministry of Interior and other Ministries,

- e-government and National Geographic Information Systems,

OTHER INSTITUTIONS

- All institutions and organizations that need momentary position information, especially professional disciplines dealing with cartography, geographic information and infrastructure,

\section{SCIENTIFIC ORGANIZATIONS - UNIVERSITY}

- Researching earth sciences and geographic information systems,

- Earthquake engineering, geophysics and seismology areas,

- Pre-awareness of earthquakes and early warning studies,

- Meteorological studies,

- Other studies in space and earth sciences.

\subsubsection{User Information}

The correction parameters issued by the CORS-TR System are published independently of the receiver. Any GNSS receiver brand and model that supports the NTRIP Protocol and has GPRS / EDGE mode can receive broadcasts of the CORS-TR system and obtain real-time location information. For this purpose, the receivers who wish to benefit from the system can receive the correction parameters from IP number 212.156.70.42 with GSM modems. As of August 4, 2017, there are 9324 subscribed users in the system and they are actively benefiting from the system (Figure 4).

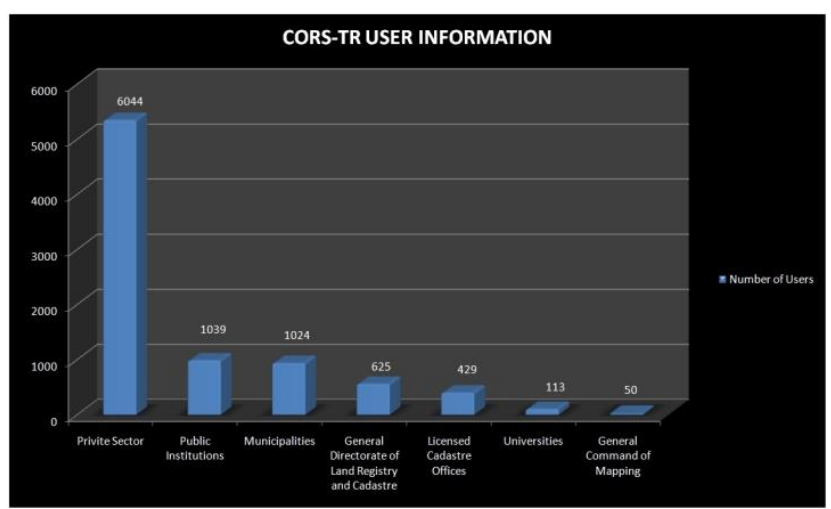

Figure 4. CORS-TR System User Information 


\section{CORS-TR SYSTEM BUSINESS STRUCTURE}

\subsection{Administrative Structure of CORS-TR System}

CORS-TR Project; was successfully transferred to GDLRC and GCM with the approval of TUBITAK in 2009 following the successful completion on 31 December 2008 at 8 December 2008.

The CORS-TR System is jointly operated by GDLRC and GCM on the protocol frame.

2.1.1 Cooperation Protocol on the Joint Operation of the CORS-TR System

A protocol consist of 31 articles about execution of CORS-TR was co-signed on July,31,2010 by GDLRC and GCM.

According the protocol, the mission of executing the CORS-TR was assigned to GDLRC. CORS-TR executive board was founded in order to take technical and administrative decision for operating of the system.

\subsubsection{CORS-TR Executive Board}

Within the scope of the Cooperation Protocol between the GDLRC and GCM on the Joint Operation of the CORS-TR System, the CORS-TR Executive Board; It is formed with the participation of at least 3 (three) personnel both from GDLRC and GCM. In addition to the regular meetings, the Board can meet and decide at any time with the call of one of the institutions in case of need. Apart from members; Specialists from other relevant institutions may be invited to the board for consultation. The Board shall take decisions by vote ballot and the decisions taken shall be executed promptly. Under the Protocol, the Executive Committee has the following powers and responsibilities;

- To determine the sales prices of all kinds of static and real-time data obtained by CORS-TR in a way to meet the operating expenses at least,

- To determine the principles regarding the provision and use of CORS-TR data of educational institutions,

- To determine the principles of maintenance, sales, handling and marketing of CORS-TR System,

- To create the plans for development, investment and R \& D studies for the structure of the CORS-TR System.

\subsubsection{CORS-TR System Operation}

While all services in military and national security related areas are issued by GCM in operation of the CORS-TR System, all other occupational disciplines in need of geographical location and civilian users are served by GDLRC.

Users who want to use the CORS-TR System are signing the CORS-TR System End User Contract which consists of 34 items published by CORS-TR Executive Board for membership and create an account on CORS-TR System offical web page.

With CORS-TR System, for the users operating in Turkey and TRNC RTK (Monthly and Yearly), DGPS (Monthly and Yearly), 30 Sec. RINEX, 1 Sec. With RINEX, 5 (five) different product services are provided, with Coordinate and Speed Information.
All these services are provided to CORS-TR Users via web. A Support Unit has been created to support the needs of users. In order to inform the users and solve problems in emergency situations with this unit;

- Hotline 4444677 dedicated to CORS-TR System,

- E-mail service via electronic mail,

- SMS service for instant access to mobile phone users,

- Web page service at the time of registration to the system,

- Social media services are provided through social networks.

\subsection{CORS-TR System Technical Infrastructure}

\subsubsection{Published Correction Techniques}

There are 5 correction publications, VRS CMR +, VRS RTCM3.1, SAPOS FKP 2.3, RTCM3Net (MAC) and DGPS from the control center. Correction parameters are used by CORS-TR compatible GNSS receivers and can be monitored by the system in real time (Figure 5).

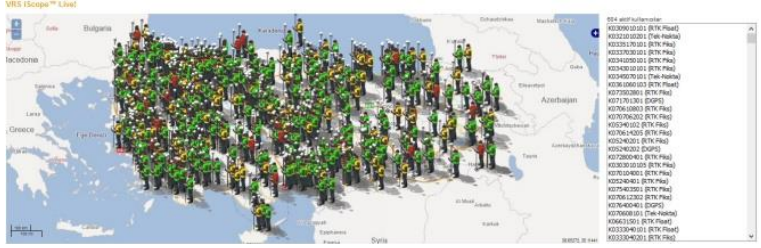

Figure 5. Real Time Monitoring of Users

\section{FKP Field Correction Technique}

In the field correction approach known as FKP (Flachen Korrectur Parameter) in the literature, atmospheric corrections and / or carrier phase corrections are calculated at each permanent station using the entire CORS-TR system network. So;

- Corrections can be used by the rover (with many different interpolation models).

- Dual / one-way communication is sufficient.

- There is no limit on the number of users.

The FKP allows the calculation of the error terms depending on the distance between the reference station and the rover, the approximate position of which is known. Where only the coordinates of the mobile and satellite information are needed, the location determination can be performed independently of the entire network. The rover receives network correction from one of the permanent stations. It identifies this station as the center in two-way communication. One-way communication method is almost not used since the user has to choose a station which is close to him. The publication form is RTCM 2.3. (Eren and Uzel, 2008)

\section{VRS Technicque}

A prerequisite for implementing Virtual Reference Stations (VRS) is the bi-directional communication between the control in the CORS-TR system network center and the rover. The rover sends approximate coordinates to the control center, and the center uses the whole network information to form the VRS reference data for the corresponding roaming position. VRS fixes obtained by the center are usually routed to the rover by RTCM. In the VRS method, corrections made from the entire network are broadcast via a virtual reference station, which is created in the 
immediate vicinity of the navigator. This virtual station is created by differential GPS (DGPS) technology. Corrections can also be calculated by taking double-differenced (double differences) from this generated virtual station. Broadcast Formats CMR +, RTCM 2.3, RTCM 3.0. Stop. (Eren and Uzel, 2008)

\section{$\underline{\text { MAC Correction Technique }}$}

MAC (Master Auxiliary Concept) The idea behind the RTCM 3.x network format is to send a subnet metering data to the rover in compressed form, and to allow the rover to make its own network calculations for different error sources. However, a disadvantage of this is that only the data belonging to only one subdivision of the network is being transmitted. Another disadvantage of the RTCM 3.0 network theory is that only ionospheric and geometric errors of a certain time are sent. When the rover starts to receive direct server data, it can not have any immediate knowledge of the systematic effects. In ionospheric and especially tropospheric models, time is needed to determine the parameters. It takes 15 minutes or more to reach a good model accuracy. Barely, during this time systematic faults can be modeled at the required safe level. (Eren and Uzel, 2008)

The RTCM 3.x networking method does not use the complex filter state created in the network server. It uses only the ambiguity obtained from the server and removes them from the carrier phase measurements (Carrier Phase). In other words, the MAC design is to transmit the carrier phase data of the external stations and the code and carrier phase data of the base station by pre-extracting the uncertainties. This domain is roaming;

- Simple interpolation of geometric and ionospheric effects,

- A complex model containing all the error sources before the network server translates the network information into the RTCM 3.0 network recommendation format will create a similar model.

\subsubsection{Periodic Measurement Check}

Periodic check measurements from the CORS-TR System are carried out centimeter accuracy periodically at an average of 700 ground control points, twice a year for 6-month periods (Fig. 6). Periodic check measures, homogeneous distribution, and positional accuracy are measured based on the CORS-TR system of previously approved ground control points, and the result of the evaluation of the difference results of the position information obtained by the existing approved position information is checked.

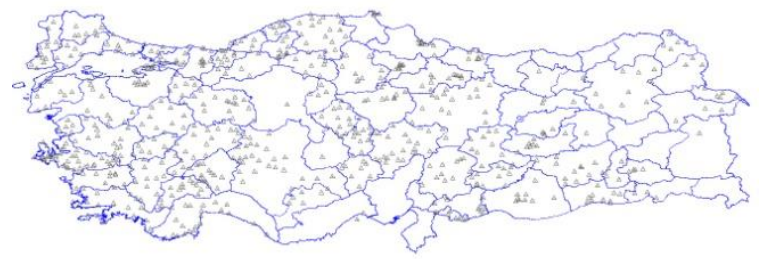

Figure 6. Distribution of 700 Ground Control Points measured by CORS-TR System

The accuracy of the CORS-TR System is obtained by calculating the difference between the location information of 3 different vector locations of the location check points approved by the location information, and the location information measured from the CORS-TR system, separately for each vector with the Calculation of the Mean Square Error (MSE). The result difference table according to years is given in Table 1 .

\begin{tabular}{|c|c|c|c|c|}
\hline PERIOD & $\begin{array}{c}\text { POINT } \\
\text { NUMBER }\end{array}$ & $\begin{array}{c}\text { RIGHT } \\
\text { VALUE } \\
(\mathbf{m} .)\end{array}$ & $\begin{array}{c}\text { UP } \\
\text { VALUE } \\
(\mathbf{m} .)\end{array}$ & $\begin{array}{c}\text { h- } \\
\text { Ellipsoid } \\
\text { (m.) }\end{array}$ \\
\hline $\begin{array}{l}\text { 2014-01 } \\
\text { SEPTEMBER }\end{array}$ & 723 & 0.0309 & 0.0301 & 0.0780 \\
\hline $\begin{array}{l}\text { 2015-1 } \\
\text { MARCH }\end{array}$ & 743 & 0.0332 & 0.0352 & 0.0468 \\
\hline $\begin{array}{l}\text { 2015-2 } \\
\text { SEPTEMBER }\end{array}$ & 718 & 0.0305 & 0.0278 & 0.0588 \\
\hline $\begin{array}{l}2016-1 \\
\text { MARCH }\end{array}$ & 725 & 0.0324 & 0.0309 & 0.0505 \\
\hline $\begin{array}{l}\text { 2016-2 } \\
\text { SEPTEMBER }\end{array}$ & 697 & 0.0286 & 0.0282 & 0.0456 \\
\hline
\end{tabular}

Table 1: Periodic Check Measures results difference table by years.

\subsection{Financial Structure of CORS-TR System}

\subsubsection{Installation Cost of CORS-TR System}

By the Scientific and Technological Research Council of Turkey; Public Institutions Research and Development Projects Support Program (1007 Program) was initiated in accordance with the decision taken at the "Science and Technology Higher Board (BTYK)" meeting held on March 10, 2005 in order to meet the needs of public institutions that could be resolved with R \& D or solve their problems. Within the scope of this project, Istanbul Kultur University, GDLRC and GCM applied together with CORS-TR Project and the project was realized in 2008 with a cost of 6.6 million USD.

\subsubsection{Operational Expenses of CORS-TR System}

Operating costs of the CORS-TR System; Hardware, software, maintenance / repair, communication and promotion expenses.

Hardware Expenses; All stations and their spare parts belonging to CORS-TR System and all electronic and mechanical devices and spare parts used in control centers are classified as hardware. There is a need to update and refurbish the hardware when the time and technology advance and when the system can not provide the necessary data for the continuity of the system. All requirements related to hardware are purchased with the decision of the Executive Board.

Software Expenses; In order to provide CORS-TR System continuous and healthy service to its users, software of all equipments must be kept up to date.

Maintenance / Repair Expenses; Maintenance and repair of all stations and spare parts of CORS-TR System and all electronic and mechanical devices and spare parts used in control centers and station relocations are evaluated within this scope. All the maintenance / repair requirements are procured within the scope of maintenance and repair contract made with the decision of the Executive Board.

Communication Expenses; All the networks used in the communication between the stations and the control centers of the CORS-TR System, between the control centers and the users, 
and the networks that support the users other than the system operation are paid to the Revolving Fund Directorate of the General Directorate of Land Registry and Cadastre.

Promotion Expenses; All the seminars, symposiums, trainings, etc. for introducing CORS-TR System to all existing and potential users, giving information about the system and giving training about usage and Organizations. The Board of Directors decision is required regarding all the training needs.

\subsubsection{Operating Revenues of CORS-TR System}

CORS-TR System continued free of charge until June 15, 2011. From this date, it was charged in order to the expenses mentioned in 2.3.2. and to provide the service to the users effectively and efficiently. CORS-TR System services provided to the user; On a unit price determined by the decision of the Executive Board and approved by the Coordination and Planning Board of Map Works between ministries without any purpose for profit.

30 Sec. RINEX service and Coordinate and Speed information are available free of charge to the users. 1 Sec. RINEX data is provided at a $75 \%$ discount to universities and public institutions. Fees applied for other services are set in 2011 and then reduced in 2012. Since the revenues obtained between the years 2012 2016 cover the expenses, no wage increase has been made. The wages applied as of since 2012 are shown in Table 2 and the annual income amounts obtained in 2011-2016 are shown in Table 3 .

\begin{tabular}{|c|c|c|c|}
\hline TYPE OF SERVICE & DATA TPPE & FEES & EXPLANATION \\
\hline Registration Fee & . & $\$ 42,00$ & One-off \\
\hline \multirow{4}{*}{ RTKFEES } & \multirow{2}{*}{ Web-RTK } & $\$ 28,00$ & Monthly \\
\hline & & $\$ 210,00$ & Annual \\
\hline & \multirow{2}{*}{ Web-DGPS } & $\$ 14,00$ & Monthly \\
\hline & & $\$ 105,00$ & Annual \\
\hline \multirow{2}{*}{ STATIC DATA } & Rinex 1 Sec. & $\$ 0,14$ & Station/Hour \\
\hline & RINEX 30 Sec. & Free & Station/Day \\
\hline
\end{tabular}

Table 2: CORS-TR System Usage Fees.

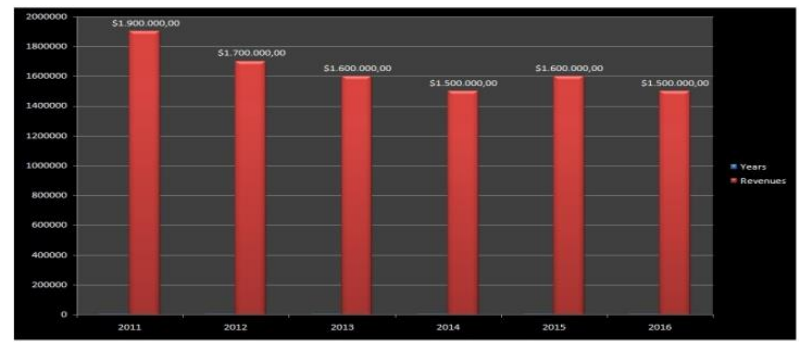

Table 3: CORS-TR System Revenue between 2011 and 2016

\section{CORS-TR SYSTEM GAINS OBTAINED IN OPERATION}

\subsection{Cost analysis}

\subsubsection{Installation and Operation Expenses}

System operation is continuously monitored so that CORS-TR System can provide uninterrupted, effective and correct information to the user. Maintenance and repair are done in a timely and fast manner in order to ensure that the hardware and software are up-to-date and operate smoothly. Communication services are provided by following uninterrupted and technological developments. Security precautions are taken against the cyber attack. For this, investments are made in the field of security.

The disclosures of the expenses incurred within the framework of the CORS-TR System between the years 2010 and 2016 are given in Table 4.

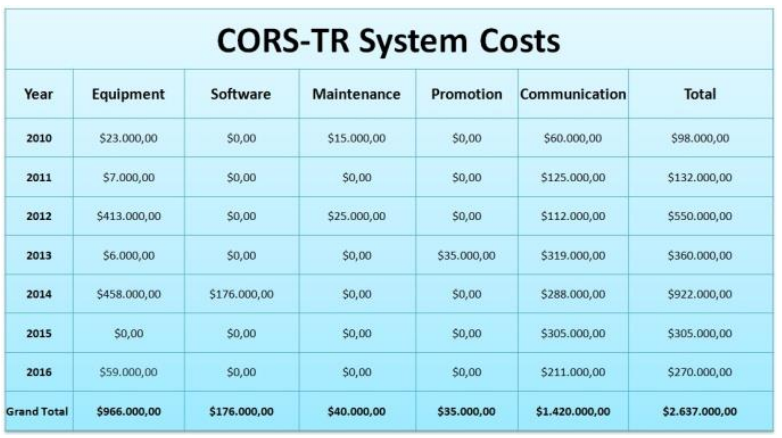

Table 4: CORS-TR System Expenditures between 2010 and 2016

\subsection{Communication Model Analysis}

In the CORS-TR System project establishment, the data communication between the control centers and the permanent stations is provided via the ADSL (Asymmetric Digital Subscriber Line) network and in case of any problems in the ADSL network as a backup over the $3 \mathrm{G}$ mobile network.

In this communication model, a different communication model is planned due to the interruptions in data. Turk Telekom A.S. Point-to-Point VPN Network was established and continuous communication was provided between permanent GNSS stations and control centers.

Mobile network communication, which is used as a backup data communication of stations in 2015 , is also included in the mobile VPN system, ensuring that the system-wide communication is fast and secure.

\subsection{Security Analysis}

In the establishment of CORS-TR system, system security is provided by system security software. During the operation of the system, DDoS (Distributed Denial of Service Attack) attacks were exposed and the services provided to the users due to these attacks were affected. In order to prevent DDoS attacks, UTM devices have been installed to provide uninterrupted service to the system.

In addition, system securityis supported with Firewall and antivirus devices. Studies have begun on obtaining of the programs that enable patching the patches of the programs used in the system and follow the work done on the servers.

\subsection{Technique Analysis}

CORS-TR System users can have $\pm 4 \mathrm{~cm}$ accuracy within seconds by using the Network-RTK method and do not need a second permanent GNSS receiver or a second person for this. 
Approximately 8,000 GNSS receivers used nationwide have been increased performance by $50 \%$ and to work on all geographic information technologies. With the CORS-TR System, cadastral and geodetic studies throughout Turkey are carried out quickly and economically without the need for a local permanent reference point, topographical studies are in real time.

Moreover, in Turkey, which is an earthquake country determination of the speeds of the movements of the geodetic points and the tectonic plate movements are realized.

At present, Large Scale Map and Map Information Production Regulation is used for geodetic infrastructure standards in our country. Static GNSS sessions and a C-rated Ground Control Point facility and production are described in the relevant articles of this directive. According to the provisions of the "Cadastral Map Production and Control" Circular No. 2010/11 published by GDLRC, it became possible to produce C-rated Ground Control Point by using CORS-TR System, regardless of point hierarchy and distance. In this case, prior to the field studies, the discovery of the point which's coordinates are known was abandoned, which contributed to the saving by preventing the loss of time, personnel and money (Figure 7).
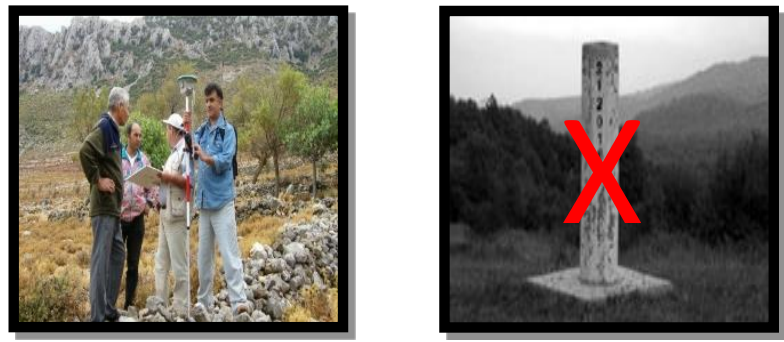

Figure 7. C-Rated Ground Control Point Static GNSS Measurement

In terms of details, the CORS-TR System measures about 15 million points per year, which is a striking result of these contributions (Figure 8).

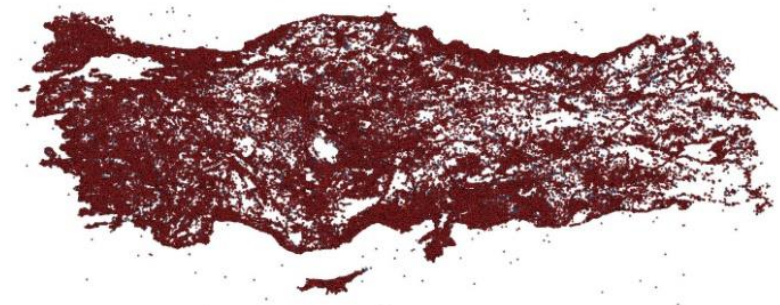

Figure 8. 2016 Year CORS-TR System Usage Map

Map and cadastral work do not require the installation and measurement of triangles and polygons that make up 30\% of the time and cost, saving around 35 million USD annually in map studies approximately $\$ 220$ million allocated annually.

\subsection{User Analysis}

Users who benefit from different occupational disciplines from the CORS-TR System are grouped under 7 different headings. As of February 10, 2017, the system benefits from 8455 different users.
There are 81 cities in Turkey and in 47 of them, there are 104 users belonging to 58 different universities.

There are 989 users from 42 different public institutions.

The sectoral distribution of the users of the system, other than the GDLRC and GCM, is given in Figure 9.

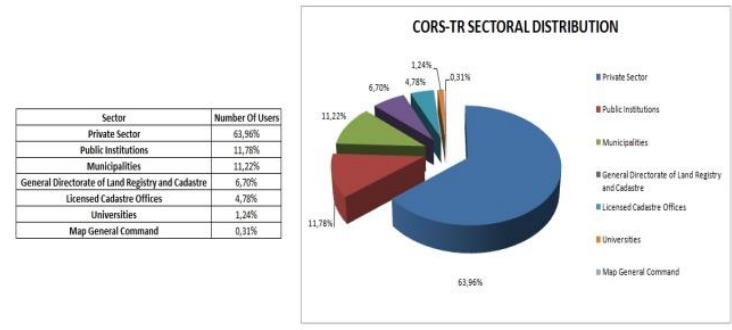

Figure 9. CORS-TR System Users

Any brand or model that supports NTRIP protocol and RTCM dataset structure can benefit from GNSS receivers CORS-TR system. In CORS-TR system 21 different GNSS brand devices are used. The distributions of these devices in the system are shown in Figure 10.

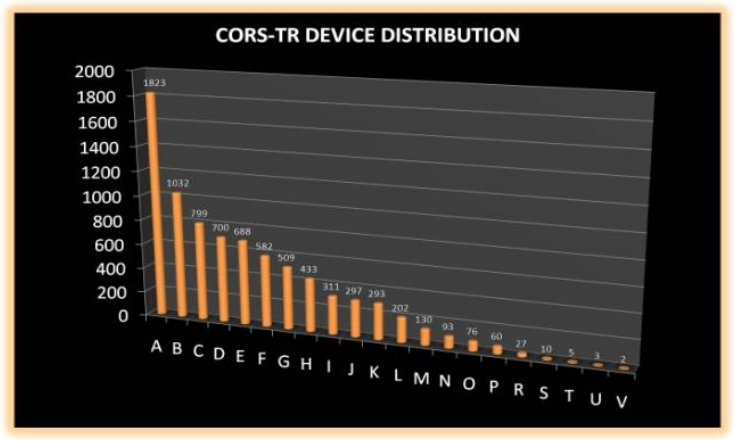

Figure 10. Subscriber to CORS-TR System by GNSS receivers

\section{CORS-TR SYSTEM FUTURE OVERVIEW}

\subsection{Software Goals}

In the first establishment of CORS-TR system, the system was activated by choosing the most appropriate software for the day and loading it into the system. Since the day the system was installed, problems that have occurred have been removed as soon as possible by keeping system programs under constant control and necessary precautions have been taken for the problems that may arise.

Depending on the development of the technology, all the programs used in the system (operating system, communication, process programs, etc.) are constantly developing and publishing new updates. These software updates are continuously monitored to ensure that the system does not interfere with its current operation and to ensure that it works properly, updates are evaluated first and then, after the appropriateness is checked, updates are made. In 2014, the transition process to 64-bit software was completed instead of 32-bit software in the whole system. Adaptation of the system will be ensured by following the changes in the technology in the coming period. 


\subsection{Hardware Goals}

When the CORS-TR system control centers are installed, the CPU, RAM and hard disks are selected in order to ensure efficient operation of the system and the most suitable configuration for system operation has been established.

Depending on the technological developments, the servers and internal configurations of the system were updated in 2014.

With this update, the system has been able to provide continuous and efficient service to the users.

\subsection{Communication Goals}

CORS-TR System Communication between the control centers and 146 stations in Turkey and TRNC is provided by VPN network communication structure. General communication of the system is constantly monitored and any problems that arise are detected instantaneously and corrected by intervention in the shortest possible time and the update of general communication is kept under control for possible problems.

In CORS-TR system, as well as existing communication solutions used now, suitable solutions are tested by following developments in technology, by considering system compatibility and benefit / cost analysis. The use of channel bonding with the MultiChannel VPN router is a sample, which is thought to be able to provide system communication more quickly and seamlessly. Tests are carried out on these 4 stations located in the TRNC.

\subsection{Security Goals}

The system is kept under constant control by the existing security systems and the system security against the possible problems and the possible attack is ensured. Technological developments are monitored and the necessary updates, patches and new versions for system security are followed and necessary updates are planned.

\section{CONCLUSION}

The Turkish National Stationary GNSS Network-Active (CORSTR) System consists of 146 permanent GNSS stations and Control and Analysis Centers that are established in Turkey and in the Turkish Republic of Northern Cyprus (TRNC) in order to determine the location information in centimeter accuracy and in real time (RTK).

CORS-TR has been serving the increasing number of institutions and users from 2009 to the present day. As of February 10, 2017, it provides service to 8475 users including Private Sector 5844, GDLRC 560, Public Institutions 989, Municipalities 952, Universities 104 and GCM 26. Any brand and model of GNSS receivers supporting the NTRIP (Networked Transport of RTCM via Internet Protocol) protocol and RTCM (The Radio Technical Commission for Maritime Services) dataset structure can benefit from the CORS-TR System.

Within the scope of measurement and improvement of service quality in CORS-TR system; The system is tested periodically twice a year and in this scope, test measurements are made twice a year at approximately 700 points which's coordinates are known.
Significant experiences were obtained during the operation of the CORS-TR System, which started to be established in 2006 and which has been serving users since 2009. Within the scope of these experiences;

The CORS-TR System was established with a cost of 6.6 million USD, and the operating expenses of the system are covered within the scope of system updates, maintenance, repair and substitution works, communication and security services. With the CORS-TR System, around 8,000 GNSS Users' performances across the country increased by $50 \%$, saving $30 \%$ in time and cost of geodetic work for all projects that require location information. Within the scope of Turkey, cadastral renewal studies with a budget of 220 million USD continue and $30 \%$ of these studies are calculated as geodetic studies. It can be seen that the geodetic works carried out from the CORS-TR system without the Ground Control Point have saved about 35 million USD.

CORS-TR System is a communication project at the same time as well as a geodesy project. The system should provide continuous data flow between the Stationary GNSS Stations and the Control Center with a delay of no more than 0.6 seconds. During the installation phase of the system, communication model was provided with ADSL. In order to prevent the discontinuities and delays experienced in data flow, Turkish Telecommunication Inc. The data flow is seamlessly provided from the point-to-point VPN model. The VPN model is also supported by the GPRS / EDGE model for backing up the data communication model.

In CORS-TR System, the communication model between the permanent GNSS Stations and the Control Center and between the Users and Control Center is an important issue in terms of operating the system. The system uses UTM device to prevent DDOS attacks in particular, and system security is also provided by Firewall and AntiVirus security software and patches.

Technological developments and rapid changes have brought convenience in many occupational disciplines, thus saving considerable time and cost. The technological developments in CORS-TR System, especially developments in software, hardware, communication and security issues, are closely monitored and necessary updates are made.

With the 719th Article of the Civil Code No. 4721, "The boundaries of the immovable are determined by the title marks and border marks on the supply. If the land plans and the signs on the supply do not coincide, the actual boundary is the plan." In this context; It is the foundation of the created plans based on solid bases. With the CORS-TR System, the country horizontal control network is firmly established and other institutions and organizations, especially GDLRC, are making plans with this infrastructure.

CORS-TR System is used in whole country and TRNC especially in the construction of maps of many investment projects such as Express Railways, Highways, Bridges and Viaducts, Dam Construction, Energy Transmission Lines, Hydroelectric Power Plant and Wind Power Plant Construction and increasing its importance every day.

The CORS-TR System has been operated by public employees since 2009 , and the model of operation of the system by the service procurement method from the private sector under the control of experienced public personnel can be considered. 


\section{REFERENCES}

19512 Say1lı ve 09 Temmuz 1987 Tarihli Resmi Gazetede yayımlanmış 3402 Kanun Numaralı Kadastro Kanunu.

Ç.Mekik, Ö.Salgın, İ.Cankurt, S.Ergüner, H.B.Ateş Ve T.Kara, GPS/IMU Verilerinin TUSAGA-Aktif Sisteminin Sabit İstasyon Verileri İle Process Edilerek Resim Orta Noktası Koordinat Değerlerinin Belirlenmesi, TUFUAB VI. Teknik Sempozyumu, 2011

E. Ayyıldız, M. V. Gezer, Z. S. Karan, E. Kulaksı,, B. Erkek Ve S. Bakıcı (2014) TUSAGA-Aktif Sistemi ve Kullanıcı Profili Analizi, 7.Mühendislik Ölçmeleri Sempozyumu, 2014

K. Eren ve T. Uzel, Ulusal Cors Sisteminin Kurulması ve Datum Dönüşümü Projesi, TUSAGA-Aktif (CORS-TR): 3.Çalıştay, 2008

Tapu ve Kadastro Genel Müdürlüğü - Harita Dairesi Başkanlığı Eğitim Notları, http://www.tkgm.gov.tr/tr/harita

Tapu ve Kadastro Genel Müdürlüğü - TKGM 2014 Y11 Kurumsal Mali Durum ve Beklentiler Raporu, https://www.tkgm.gov.tr/tr/icerik/tkgm-2014-yili-kurumsalmali-durum-ve-beklentiler-raporu

Tapu ve Kadastro Genel Müdürlüğü - Kadastro İşlemleri Rehberi 2011, http://www.tkgm.gov.tr/tr/sayfa/yayinlarimiz-0 